\title{
New Prognostic Biomarkers of Mitochondrial Oxidative Stress in Septic Patients
}

\author{
Leonardo Lorente $\mathrm{e}^{1, *}$ \\ ${ }^{1}$ Intensive Care Unit, Hospital Universitario de Canarias, La Laguna, Spain \\ *Corresponding author: Leonardo Lorente, Intensive Care Unit, Hospital Universitario de Canarias, La Laguna, Spain. Tel: +34-922679141, Fax:+34-922647112, E-mail: lorentemartin@msn.com \\ Received: March 1, 2015; Accepted: May 10, 2015
}

\begin{abstract}
Context: Sepsis is a common, expensive, and frequently fatal condition that is associated with as many deaths annually as is acute myocardial infarction.

Evidence Acquisition: Sepsis could alter different pathways and cause inflammation, coagulation, apoptosis, and mitochondrial oxidative stress and dysfunction. This review focuses on new prognostic biomarkers of mortality due to mitochondrial oxidative stress in septic patients.

Results: Recently some biomarkers of mitochondrial oxidative stress have been associated with prognosis in septic patients; they include circulating levels of malondialdehyde, total antioxidant capacity, melatonin level, platelet level of cytochrome c oxidase (COX) or mitochondrial respiratory complex IV, and mitochondrial deoxyribonucleic acid (mtDNA) haplogroup.

Conclusions: Some biomarkers of mitochondrial oxidative stress (e.g. circulating levels of malondialdehyde, total antioxidant capacity, melatonin level, platelet level of COX, mtDNA haplogroup) have been recently associated with mortality in septic patients. These biomarkers could assist in the prognostic classification of septic patients and open new research lines in their treatment.
\end{abstract}

Keywords: Biomarkers; MDA; TAC; Melatonin; COX; mtDNA; Sepsis; Mortality

\section{Context}

Sepsis represents the immune system's systemic response to infection. Severe sepsis is a common, expensive, and frequently fatal condition that is associated with as many deaths annually as is acute myocardial infarction $(1,2)$. In the USA, the average cost per sepsis case is estimated at $\$ 20,000$, with a total national cost of $\$ 16.7$ billion per year. Hospital mortality rates due to sepsis are around $29 \%$, with 215,000 deaths per annum in the USA (2).

\section{Evidence Acquisition}

Sepsis could cause alterations in different pathways and result in inflammation, coagulation, apoptosis, and mitochondrial oxidative stress and dysfunction. This review focuses on new prognostic biomarkers of mortality risk in septic patients due to mitochondrial oxidative stress.

\section{Results}

\subsection{Circulating Levels of Malondialdehyde}

Sepsis is characterized by a hyperoxidative state (3-9), which results from an imbalance between oxidants, such as reactive oxygen species and reactive nitrogen species, and antioxidant compounds, such as glutathione reductase and superoxide dismutase. This hyperoxidative state damages lipids and proteins, impairs normal cellular function, and induces apoptosis.

Oxidative stress induces the peroxidation of membrane lipids, which generates a variety of decomposition end products such as malondialdehyde (MDA). MDA is a lowmolecular-weight aldehyde that results from free radical attacks on polyunsaturated fatty acids during the degradation of cellular membrane phospholipids. MDA is released into the extracellular space and finally into the blood; it has, therefore, been used as an effective biomarker of lipid oxidation $(8,9)$.

The oxidant and antioxidant state in septic patients has been assessed only in small series (10-18). A high antioxidant state, determined by different compounds, has been found in non-surviving septic patients by comparison with their surviving counterparts (10-12). Also, high serum MDA levels have been detected in septic patients vs healthy controls (13-16). In this regard, Ogilvie et al. (13) studied 12 severely septic patients and found that serum MDA levels were higher in non-surviving septic patients than in surviving ones; however, the sample size was too

Copyright (C) 2015, Shahid Beheshti University of Medical Siences. This is an open-access article distributed under the terms of the Creative Commons AttributionNonCommercial 4.0 International License(http://creativecommons.org/licenses/by-nc/4.0/) which permits copy and redistribute the material just in noncommercial usages, provided the original work is properly cited. 
small to demonstrate whether there was an association between serum MDA and mortality in severely septic patients.

In a study conducted by our team (with a larger sample size and comprising 228 severely septic patients), serum levels of MDA were higher in severely septic patients than in healthy controls and serum MDA levels were higher in non-surviving septic patients than in surviving ones upon the diagnosis of severe sepsis. The novel findings of our study were comprised of associations between serum MDA levels and several indicators of severity in sepsis (viz, lactic acid levels, sequential organ failure assessment [SOFA] score, acute physiology and chronic health evaluation II [APACHE-II], international normalized ratio, activated partial thromboplastin time, tumor necrosis factor alpha [TNF- $\alpha$ ], interleukin-10 [IL-10]) upon the diagnosis of severe sepsis and also associations between serum MDA levels upon the diagnosis of severe sepsis and mortality in septic patients (19). Our Cox regression analysis revealed that MDA serum levels were associated with survival at 30 days (hazard ratio, 1.05; 95\% confidence interval [CI], 1.009 to 1.091; $\mathrm{P}=0.016)$ after controlling for age, lactic acid levels, APACHE-II, and activated partial thromboplastin time. In the Kaplan-Meier survival analysis, we found that patients with serum MDA levels higher than $4.11 \mathrm{nmol} / \mathrm{mL}$ had a lower probability of survival at 30 days (log-rank, 18.1; hazard ratio, 2.4 ; $95 \% \mathrm{CI}, 1.49$ to 3.94 ; $\mathrm{P}<0.001$ ) than patients with lower levels. The receiver operating characteristic (ROC) analysis showed that the area under the curve of serum MDA levels to predict 30-day survival was 0.62 ( $95 \% \mathrm{CI}, 0.56$ to $0.69 ; \mathrm{P}=0.002$ ).

Afterward, we sought to analyze serum MDA levels during follow-up. In another study by our team on 328 severely septic patients (to our knowledge, the largest series providing data on oxidative stress in septic patients), we reported novel findings as follows: (a) septic patients showed higher MDA serum levels than did healthy controls during the first week post diagnosis, (b) non-survivors exhibited persistently higher serum MDA levels than did survivors during the first week post diagnosis, and (c) there was an association between serum MDA levels and several indicators of severity in sepsis (including lactic acid and the SOFA score) during the first week post diagnosis (20). Previous studies have reported a positive correlation between MDA and severity in septic patients (16-18). Andresen et al. (16) reported that there was a positive correlation between peak MDA and peak lactate levels and that the peak MDA level occurred at 72 hours; however, there was no correlation at day 1. In a study by Goode et al, patients with 3 or more failing organs showed higher MDA levels than did patients with fewer failing organs (18). Thus, the new finding of our study was a positive correlation between serum MDA levels and sepsis severity at day 1 and during the first week following diagnosis.
Our findings indicate that non-surviving septic patients have a higher hyperoxidative state and that this clinical situation may progress to cellular dysfunction, organ failure, and finally death.

\subsection{Circulating Levels of Total Antioxidant Capacity}

In the strategy to maintain redox balance, antioxidant compounds within cells and in extracellular fluids can be upregulated and mobilized to neutralize the excessive formation of reactive oxygen species. Antioxidant compounds are transported and redistributed by the blood to every part of the body (21) and exert their function by receiving an electron from a radical or donating an electron to a radical with the consequent formation of stable products. Antioxidant compounds do not work alone, but rather they establish complex interactions with one another (22). Accordingly, the measurement of total antioxidant capacity (TAC) in the serum or plasma may yield better information on the patient's antioxidant status than that obtained from measuring concentrations of individual compounds (23).

Circulating TAC levels have been assessed in critically ill patients (24-28) and severely septic patients $(10,12$, 29-31) in studies with limited numbers of subjects and with contradictory results. Moreover, no association has been found between serum TAC levels and mortality in patients with sepsis. In a study carried out by our team on 213 severely septic patients (to our knowledge, the largest series providing data on serum TAC in septic patients), we found that serum TAC levels were higher in non-survivors than in survivors. The novel finding of our study was that serum TAC levels were associated with mortality in severely septic patients (32). Our Cox regression analysis revealed that serum TAC levels were associated with survival at 30 days (hazard ratio, 1.50 ; 95\% CI, 1.16 to $1.94 ; \mathrm{P}=0.002$ ) after controlling for lactic acid levels, APACHE-II score, and renal failure. The ROC analysis showed that the area under the curve of serum TAC levels to predict 30-day survival was 0.61 ( $95 \%$ CI, 0.545 to $0.680 ; \mathrm{P}=0.04$ ). In the Kaplan-Meier survival analysis, we found that patients with serum TAC levels higher than $2.80 \mathrm{mmol} / \mathrm{L}$ had a lower probability of survival at 30 days (log-rank, 7.5; hazard ratio, 2.1; $95 \% \mathrm{CI}, 1.03$ to $4.28 ; \mathrm{P}=0.006$ ) than did patients with lower levels. Additionally, we found a positive correlation between serum TAC and MDA levels (rho, 0.16; P = 0.02 ). These data suggest that the increased antioxidant capacity observed in non-survivors is a host response to severely propagating oxidative stress. These findings indicate that non-surviving, compared to surviving, septic patients have an increased production of oxidant species and that the increased antioxidant capacity attempts to compensate for the high production of free radicals to maintain the balance between the oxidant and antioxidant state. Nonetheless, in non-surviving septic patients, this increased antioxidant capacity is 
not enough to compensate for the high production of oxidant species leading to high peroxidation and finally organ dysfunction and death.

\subsection{Circulating Levels of Melatonin}

Melatonin is a lipophilic amino acid derived from tryptophan and is synthesized by the pineal gland with a circadian rhythm with high values during the night time and low values during the day time. Additionally, melatonin is synthesized in other organs such as the retina, gastrointestinal tract, and thymus as well as in bone marrow and lymphocytes, but without circadian rhythm. Melatonin has a very short half-life and is predominantly metabolized to 6-sulfatoxymelatonin in the liver and is excreted in urine. Melatonin is involved in the regulation of sleep; moreover, it has anti-inflammatory, antioxidant, and antiapoptotic effects and preserves mitochondrial function (33-43).

However, melatonin in septic patients has been scarcely explored only in studies with small sample sizes (maximum 20 patients) and the findings appear contradictory (44-50). In a study on 14 septic patients, there was a negative correlation between the APACHE-II scores and serum melatonin levels (48). In contrast, in another study on 20 septic pediatric patients, serum melatonin concentrations were higher in septic patients than in controls, and in non-surviving septic patients than in surviving ones (47).

In a study performed by our team on 201 severely septic patients (to our knowledge, the largest series providing data on serum melatonin levels in septic patients), we found that non-survivors had higher serum levels of melatonin, MDA, and IL-6 than did survivors. The novel finding of our study was that serum melatonin levels were associated with severity, oxidant state, inflammatory state, and mortality in septic patients (51). In the ROC analysis, we found that the area under the curve of serum melatonin levels to predict 30-day survival was 0.66 (95\% CI, 0.583 to $0.730 ; \mathrm{P}<0.001$ ). Our Kaplan-Meier survival analysis revealed that the risk of death in septic patients with serum melatonin levels higher than $19.5 \mathrm{pg} / \mathrm{mL}$ was higher than that in patients with serum melatonin levels lower than $15.6 \mathrm{pg} / \mathrm{mL}$ (hazard ratio, 2.3; 95\% CI, 1.34 to 3.93; $\mathrm{P}<0.001)$. In the multiple logistic regression analysis, we found that serum melatonin levels were associated with 30-day mortality (odds ratio [OR], 1.022; 95\% CI, 1.001 to 1.043; $\mathrm{P}=0.04$ ), controlling for serum TNF- $\alpha$ levels, serum IL-6 levels, and age. In addition, serum melatonin levels were positively associated with serum levels of MDA, IL-6 and lactate levels, and the SOFA score.

These findings indicate that in non-surviving septic patients, with increased inflammatory and oxidative state, the increase in serum melatonin levels is insufficient to compensate for this undesirable situation.

From a therapeutic perspective, the development of the modulators of the antioxidant and oxidant state could be used as a new class of drugs for the treatment of severe sepsis. In this regard, melatonin has different potential benefit effects (33-43). Melatonin exhibits anti-inflammatory effects because it decreases the liberation of proinflammatory cytokines (e.g. IL-6, IL-8, TNF- $\alpha$ ) and increases the liberation of anti-inflammatory cytokines (e.g. IL-10). Melatonin also has an antioxidant effect in that it causes the upregulation of several antioxidant enzymes (e.g. glutathione reductase) and is a potent scavenger of reactive oxygen species. In addition, melatonin has an antiapoptotic action inasmuch as apoptotic cell death could be activated by the intrinsic or mitochondrial pathway by reactive oxygen species and melatonin has an antioxidant action. Furthermore, the antioxidant effects of melatonin also prevent reactive oxygen species from damaging mitochondrial deoxyribonucleic acid DNA (mtDNA) and the mitochondrial respiratory enzyme complex. In rats, the administration of melatonin has been shown to reduce MDA levels, increase the levels of other antioxidant compounds (e.g. glutathione reductase, superoxide dismutase), improve mitochondrial function, decrease TNF- $\alpha$ and IL- 6 levels, decrease nitric oxide, reduce biochemical markers of organ dysfunction, and increase survival rates (52-60). In patients, the use of melatonin has reduced MDA serum levels in asphyxiated newborns (61), septic newborns (50), and adult burn patients (62). In a study by Fulia et al. (61) 20 asphyxiated newborns were randomized to receive melatonin: Patients treated with melatonin showed lower serum levels of MDA and nitrite/nitrate (associated with vasodilatation) levels. In a study by Gitto et al. (50), 20 septic newborns were randomized to receive melatonin: Those treated with melatonin showed lower serum levels of MDA and 4-hydroxylalkenals (another lipid peroxidation product). In a study by Sahib et al.(62), 180 burn patients were randomized to receive different antioxidants (viz, vitamins $\mathrm{E}$ and C, zinc sulfate, allopurinol, melatonin, N-acetylcysteine): Patients receiving antioxidants showed lower serum MDA levels, higher levels of glutathione (a natural antioxidant), and lower mortality rates.

\subsection{Platelet Levels of Cytochrome C Oxidase or Mi- tochondrial Respiratory Complex IV}

The results of different studies have suggested that another physiopathological mechanism that occurs in sepsis is the impaired cellular oxygen utilization, known as cytopathic hypoxia (63). In this regard, elevated levels of skeletal muscle $\mathrm{PO}_{2}$ have been found in patients with severe sepsis $(64,65)$. Moreover, non-survivors of sepsis exhibit impaired capacity to increase tissue oxygen consumption in response to a rise in oxygen delivery (66).

Cytopathic hypoxia is caused by the deregulation of oxygen metabolism due to impaired cellular oxygen utilization secondary to mitochondrial dysfunction. Most of the cellular oxygen delivered to tissues is used by the mitochondrial respiratory chain of the oxidative phos- 
phorylation (OXPHOS) system to produce ATP. There are 5 respiratory chain enzyme complexes required for ATP production by the OXPHOS system: nicotinamide adenine dinucleotide dehydrogenase-coenzyme Q10 oxidoreductase or complex I, succinate-coenzyme Q10 oxidoreductase or complex II, cytochrome c oxidoreductase or complex III, cytochrome c oxidase (COX) or complex IV, and ATP synthetase or complex V. In particular, COX or mitochondrial respiratory complex IV is responsible for most of this oxygen consumption.

The function of the OXPHOS system in septic patients has been analyzed only in studies with small sample sizes (fewer than 40 septic patients and 40 control subjects), and the results are demonstrably inconsistent (6782). Some studies have found lower activity of different mitochondrial respiratory complexes in septic patients than in control subjects in muscle biopsies (ie, biceps brachii, triceps brachii, vastus lateralis, serratus anterior), peripheral blood mononuclear cells, and circulating platelets. Some other studies have reported a decrease in mitochondrial inner membrane potential in peripheral blood mononuclear cells and circulating platelets in septic patients vs control subjects. In addition, there have been investigations reporting low oxygen consumption in muscle biopsies and in peripheral blood mononuclear cells in septic patients vs control subjects, whereas some others have found high oxygen consumption in circulating platelets and peripheral blood mononuclear cells in septic patients vs control subjects. Moreover, the small sample size of all those studies precluded the establishment of an association between the function of the OXPHOS system and mortality in septic patients.

We carried out a study to determine COX activity and quantity in a larger series of septic patients (comprising 96 severely septic patients) and to avoid the need to obtain biopsies from critically ill patients. We drew upon a less invasive protocol using circulating platelets. The main finding of our study was an association between platelet COX activity and COX quantity determined upon the diagnosis of sepsis at a 6-month survival (83). We found that the area under the curve of the COX quantity to predict 6-month survival was 0.67 ( $95 \% \mathrm{CI}, 0.56$ to 0.76 ; $\mathrm{P}=0.003$ ). Our Kaplan-Meier survival analysis showed that patients with a COX quantity higher than 1.88 had a higher survival rate at 6 months than did patients with a lower ratio (risk ratio, 1.89; 95\% CI, 1.20 to 3.02; $\mathrm{P}=0.01$ ). In the logistic regression analysis, we found that COX quantity $(P=0.02)$ and COX activity were associated with survival at 6 months $(\mathrm{P}=0.04)$ controlling for the SOFA, or for lactic acid and age. Another interesting finding of our study was a positive correlation between COX activity and COX quantity (rho, 0.74; $\mathrm{P}<0.001)$. These findings indicate that the decreased COX activity in non-survivors is not due to higher direct inhibition, but rather it is in consequence of lower levels of the enzyme. Another interesting finding of our study was that citrate synthase (a mitochondrial density) activities were higher in non- surviving than in surviving patients, which indicates that non-surviving individuals had impaired mitochondrial function and that they tried to compensate for the deficit in energy production by increasing mitochondrial density. Another new finding of our study was a significant correlation between platelet COX quantity and the SOFA score (rho, -0.22; $\mathrm{P}=0.036$ ).

Thereafter, we sought to analyze platelet COX activity during follow-up. In another study by our team on 198 severely septic patients (to our knowledge, the largest series providing data on the oxidative state in septic patients), we revealed that septic patients who survived 1-month had higher platelet COX activity upon sepsis diagnosis and during the first week than did non-survivors and that platelet COX activity upon sepsis diagnosis and during the first week was associated with mortality, controlling for the SOFA and lactic acid (84).

In another study carried out by our team, we revealed primarily that surviving and non-surviving severely septic patients showed lower platelet COX activity than did healthy controls during the first week following severe sepsis diagnosis (85).

Probably, platelet COX activity is not the factor that determines death in severe sepsis patients. Furthermore, the lower platelet COX activity in non-surviving sepsis patients probably mirrors a similarly low COX activity in other organs, and this situation in other organs leads to the death of the patient.

From a therapeutic perspective, patients with lower COX activity could benefit from drugs that improve mitochondrial function. In some animal models, the administration of $\operatorname{COX}(86,87)$, caffeine (88), or glutamine (89) increased COX activity, cardiac function $(86,88,89)$, and $\operatorname{survival}(87,88)$.

\subsection{Determination of Mitochondrial Deoxyribonu- cleic Acid Haplogroup}

Septic mitochondrial dysfunction occurs as a result of oxidative stress because reactive oxygen species damage mitochondria. In addition, mtDNA can influence the survival of septic patients, possibly due to the impact of mtDNA on mitochondrial function. The influence of mtDNA on the survival of septic patients has been scarcely studied (90-93).

In a study by Yang et al. (90) on 181 Chinese septic patients, the results revealed that patients with mtDNA macrolineage $\mathrm{R}$ (including mainly haplogroups $\mathrm{B}$ and $\mathrm{F}$ ) had a higher 6-month survival rate than did patients with other macrolineages.

In a study by Baudouin et al. (91) in England on 150 septic patients, the results demonstrated that patients with mtDNA haplogroup $\mathrm{H}$ had a higher 6-month survival rate than did patients with other haplogroups. Haplogroup $\mathrm{H}$ was a haplogroup of the macrolineage $\mathrm{R}$, and the other haplogroups found in macrolineage $\mathrm{R}$ were $\mathrm{U}, \mathrm{V}, \mathrm{J}$, and T. Nevertheless, the authors did not 
find haplogroups B and $\mathrm{F}$ which were obtained in the Chinese study.

In a study by our team on 96 septic patients in Canary Islands, we found that septic patients with mtDNA haplogroup JT had a higher survival rate than did those with other mtDNA haplogroups (92). In addition, we found that septic patients with mtDNA haplogroup JT had higher platelet COX quantity during the first week following sepsis diagnosis than did those with other mtDNA haplogroups.

Subsequently, we tried to validate our results and analyze another series of patients. The results of our study (to our knowledge, the largest series providing data on mtDNA and survival in septic patients comprising 96 patients of the first series and 196 patients of the second series with a total of 292 patients) confirmed that haplogroup JT septic patients had increased 30-day and 6-month survival by comparison with non-JT haplogroup patients (93). In the multiple logistic regression analysis, we found that mtDNA haplogroup JT was associated with higher survival at 30days (OR, 0.38; 95\% CI, 0.15 to $0.95 ; \mathrm{P}=0.04)$ and 6 months (OR, $0.40 ; 95 \% \mathrm{CI}, 0.17$ to $0.90 ; \mathrm{P}=0.03$ ) after controlling for age, sex, serum IL-6 levels, and the SOFA score. Our KaplanMeier analysis demonstrated that patients with mtDNA haplogroup JT had a higher survival rate at 30 days (logrank test, 5.84; $\mathrm{P}=0.016$ ) and 6 months (log-rank test, 7.90; $\mathrm{P}=0.005)$ than did patients with other haplogroup. In addition, there were no statistically significant differences between $\mathrm{J}$ and $\mathrm{T}$ sub-haplogroups in survival at 30 days (8/11 [72.7\%] vs 30/35 [85.7\%]; $\mathrm{P}=0.37)$ and 6 months $(8 / 11[72.7 \%]$ vs $27 / 35$ [77.1\%]; $P=0.99]$. Therefore, the decreased risk of death in JT haplogroup septic patients may have been due to a haplogroup JT-defining single nucleotide polymorphism (SNP) defining this cluster and not the over-representation of 1 of the 2 sub-haplogroups that integrate the cluster.

There are data showing that, under stress conditions, IL-6 mRNA is expressed more in H than in J cybrid cells (94). In addition, circulating IL-6 levels have been associated with mortality in septic patients (95). One possible explanation for this higher survival rate in patients with haplogroup JT could be a lower inflammatory response. Cybrids are cell lines that share the nuclear genetic background and only differ in the mtDNA genotype. In addition, it is known that mtDNA genetic variation can alter the expression of nuclear genes. Thus, phenotypic differences between those cybrid cells must be due to the mtDNA genotype. We investigated whether haplogroup JT patients showed lower serum IL-6 levels and found no differences in serum IL-6 levels between different mtDNA haplogroups. Nonetheless, we found an association between serum IL-6 and mortality in our septic patients, as was previously described.

\section{Conclusions}

In conclusion, some biomarkers correlated with mitochondrial oxidative stress and dysfunction (e.g. circulating levels of MDA, TAC, melatonin level, platelet level of COX, and mtDNA haplogroup) have been recently associ- ated with mortality in septic patients. These biomarkers could assist in the prognostic classification of patients and, thus, open new research lines in their treatment.

\section{References}

1. Vincent JL, Sakr Y, Sprung CL, Ranieri VM, Reinhart K, Gerlach H et al. Sepsis in European intensive care units: results of the SOAP study. Crit Care Med.2006;34(2):344-53.

2. Angus DC, Linde-Zwirble WT, Lidicker J, Clermont G, Carcillo J, Pinsky MR. Epidemiology of severe sepsis in the United States: analysis of incidence, outcome, and associated costs of care. Crit Care Med. 2001;29(7):1303-10.

3. Andrades ME, Ritter C, Dal-Pizzol F. The role of free radicals in sepsis development. Front Biosci (Elite Ed). 2009;1:277-87.

4. Andrades ME, Morina A, Spasic S, Spasojevic I. Bench-to-bedside review: sepsis - from the redox point of view. Crit Care. 2011;15(5):230.

5. Rocha M, Herance R, Rovira S, Hernandez-Mijares A, Victor VM. Mitochondrial dysfunction and antioxidant therapy in sepsis. Infect Disord Drug Targets. 2012;12(2):161-78.

6. Galley HF. Oxidative stress and mitochondrial dysfunction in sepsis. BrJ Anaesth. 2011;107(1):57-64.

7. Galley HF. Bench-to-bedside review: Targeting antioxidants to mitochondria in sepsis. Crit Care. 2010;14(4):230.

8. Draper HH, Hadley M. Malondialdehyde determination as index of lipid peroxidation. Methods Enzymol.1990;186:421-31.

9. Dalle-Donne I, Rossi R, Colombo R, Giustarini D, Milzani A. Biomarkers of oxidative damage in human disease. Clin Chem. 2006;52(4):601-23.

10. Chuang CC, Shiesh SC, Chi CH, Tu YF, Hor LI, Shieh CC, et al. Serum total antioxidant capacity reflects severity of illness in patients with severe sepsis. Crit Care. 2006;10(1):R36.

11. Guerreiro MO, Petronilho F, Andrades M, Constantino L, Mina FG, Moreira JC, et al. Plasma superoxide dismutase activity and mortality in septic patients [corrected].J Trauma. 2010;69(6):E102-6.

12. Cowley HC, Bacon PJ, Goode HF, Webster NR, Jones JG, Menon DK Plasma antioxidant potential in severe sepsis: a comparison of survivors and nonsurvivors. Crit Care Med.1996;24(7):1179-83.

13. Ogilvie AC, Groeneveld AB, Straub JP, Thijs LG. Plasma lipid peroxides and antioxidants in human septic shock. Intensive Care Med. 1991;17(1):40-4.

14. Erdem SS, Yerlikaya FH, Cicekler H, Gul M. Association between ischemia-modified albumin, homocysteine, vitamin $\mathrm{B}(12)$ and folic acid in patients with severe sepsis. Clin Chem Lab Med. 2012;50(8):1417-21.

15. Gelain DP, de Bittencourt Pasquali MA, M. Comim C, Grunwald MS, Ritter C, Tomasi CD, et al. Serum heat shock protein 70 levels, oxidant status, and mortality in sepsis. Shock. 2011;35(5):466-70.

16. Andresen M, Regueira T, Bruhn A, Perez D, Strobel P, Dougnac A, et al. Lipoperoxidation and protein oxidative damage exhibit different kinetics during septic shock. Mediators Inflamm. 2008;2008:168652.

17. Toufekoula C, Papadakis V, Tsaganos T, Routsi C, Orfanos SE, Kotanidou A, et al. Compartmentalization of lipid peroxidation in sepsis by multidrug-resistant gram-negative bacteria: experimental and clinical evidence. Crit Care. 2013;17(1):R6.

18. Goode HF, Cowley HC, Walker BE, Howdle PD, Webster NR. Decreased antioxidant status and increased lipid peroxidation in patients with septic shock and secondary organ dysfunction. Crit Care Med.1995;23(4):646-51.

19. Lorente L, Martin MM, Abreu-Gonzalez P, Dominguez-Rodriguez A, Labarta L, Diaz C, et al. Prognostic value of malondialdehyde serum levels in severe sepsis: a multicenter study. PLoS One. 2013;8(1):e53741.

20. Lorente L, Martin MM, Abreu-Gonzalez P, Dominguez-Rodriguez A, Labarta L, Diaz C, et al. Sustained high serum malondialdehyde levels are associated with severity and mortality in septic patients. Crit Care. 2013;17(6):R290.

21. Halliwell B, Cross CE. Oxygen-derived species: their relation to human disease and environmental stress. Environ Health Perspect. 1994;102 Suppl 10:5-12. 
22. Young IS, Woodside JV. Antioxidants in health and disease. J Clin Pathol. 2001;54(3):176-86.

23. Ghiselli A, Serafini M, Natella F, Scaccini C. Total antioxidant capacity as a tool to assess redox status: critical view and experimental data. Free Radic Biol Med. 2000;29(11):1106-14.

24. Cheng $\mathrm{CH}$, Huang SC, Chiang TY, Wong Y, Huang YC. Higher plasma pyridoxal phosphate is associated with increased antioxidant enzyme activities in critically ill surgical patients. Biomed Res Int. 2013;2013:572081.

25. Alonso de Vega JM, Diaz J, Serrano E, Carbonell LF. Oxidative stress in critically ill patients with systemic inflammatory response syndrome. Crit Care Med. 2002;30(8):1782-6.

26. Dasgupta A, Malhotra D, Levy H, Marcadis D, Blackwell W, Johnston D. Decreased total antioxidant capacity but normal lipid hydroperoxide concentrations in sera of critically ill patients. Life Sci.1997;60(4-5):335-40.

27. MacKinnon KL, Molnar Z, Lowe D, Watson ID, Shearer E. Measures of total free radical activity in critically ill patients. Clin Biochem. 1999;32(4):263-8.

28. Tsai K, Hsu T, Kong C, Lin K, Lu F. Is the endogenous peroxyl-radical scavenging capacity of plasma protective in systemic inflammatory disorders in humans? Free Radic Biol Med. 2000;28(6):926-33.

29. Karapetsa M, Pitsika M, Goutzourelas N, Stagos D, Tousia Becker A, Zakynthinos E. Oxidative status in ICU patients with septic shock. Food Chem Toxicol.2013;61:106-11.

30. Doise JM, Aho LS, Quenot JP, Guilland JC, Zeller M, Vergely C, et al. Plasma antioxidant status in septic critically ill patients: a decrease over time. Fundam Clin Pharmacol. 2008;22(2):203-9.

31. Pascual C, Karzai W, Meier-Hellmann A, Oberhoffer M, Horn A, Bredle D, et al. Total plasma antioxidant capacity is not always decreased in sepsis. Crit Care Med.1998;26(4):705-9.

32. Lorente L, Martin MM, Almeida T, Abreu-Gonzalez P, Ferreres J, Sole-Violan J, et al. Association between serum total antioxidant capacity and mortality in severe septic patients. J Crit Care. 2015;30(1):217 e7-12

33. Cagnacci A. Melatonin in relation to physiology in adult humans. J Pineal Res.1996;21(4):200-13.

34. Dawson D, Encel N. Melatonin and sleep in humans. J Pineal Res. 1993;15(1):1-12.

35. Galano A, Tan DX, Reiter RJ. Melatonin as a natural ally against oxidative stress: a physicochemical examination. J Pineal Res. 2011;51(1):1-16.

36. Mauriz JL, Collado PS, Veneroso C, Reiter RJ, Gonzalez-Gallego J. A review of the molecular aspects of melatonin's anti-inflammatory actions: recent insights and new perspectives.J Pineal Res. 2013;54(1):1-14.

37. Kurdi MS, Patel T. The role of melatonin in anaesthesia and critical care. Indian J Anaesth. 2013;57(2):137-44.

38. Bourne RS, Mills GH. Melatonin: possible implications for the postoperative and critically ill patient. Intensive Care Med. 2006;32(3):371-9.

39. Reiter RJ, Paredes SD, Manchester LC, Tan DX. Reducing oxidative/ nitrosative stress: a newly-discovered genre for melatonin. Crit Rev Biochem Mol Biol. 2009;44(4):175-200.

40. Srinivasan V, Mohamed M, Kato H. Melatonin in bacterial and viral infections with focus on sepsis: a review. Recent Pat Endocr Metab Immune Drug Discov. 2012;6(1):30-9.

41. Srinivasan V, Pandi-Perumal SR, Spence DW, Kato H, Cardinali DP. Melatonin in septic shock: some recent concepts. J Crit Care. 2010;25(4):656 e1-6.

42. Escames G, Acuna-Castroviejo D, Lopez LC, Tan DX, Maldonado MD, Sanchez-Hidalgo M, et al. Pharmacological utility of melatonin in the treatment of septic shock: experimental and clinical evidence. J Pharm Pharmacol. 2006;58(9):1153-65.

43. Rinaldi S, Landucci F, De Gaudio AR. Antioxidant therapy in critically septic patients. Curr Drug Targets. 2009;10(9):872-80.

44. Verceles AC, Silhan L, Terrin M, Netzer G, Shanholtz C, Scharf SM. Circadian rhythm disruption in severe sepsis: the effect of ambient light on urinary 6-sulfatoxymelatonin secretion. Intensive Care Med. 2012;38(5):804-10.

45. Li CX, Liang DD, Xie GH, Cheng BL, Chen QX, Wu SJ, et al. Altered melatonin secretion and circadian gene expression with in- creased proinflammatory cytokine expression in early-stage sepsis patients. Mol Med Rep. 2013;7(4):1117-22.

46. Mundigler G, Delle-Karth G, Koreny M, Zehetgruber M, SteindlMunda P, Marktl W, et al. Impaired circadian rhythm of melatonin secretion in sedated critically ill patients with severe sepsis Crit Care Med. 2002;30(3):536-40.

47. Bagci S, Horoz OO, Yildizdas D, Reinsberg J, Bartmann P, Muller A Melatonin status in pediatric intensive care patients with sepsis Pediatr Crit Care Med. 2012;13(2):e120-3.

48. Perras B, Kurowski V, Dodt C. Nocturnal melatonin concentration is correlated with illness severity in patients with septic disease. Intensive Care Med. 2006;32(4):624-5.

49. Alamili M, Bendtzen K, Lykkesfeldt J, Rosenberg J, Gogenur I. Melatonin suppresses markers of inflammation and oxidative damage in a human daytime endotoxemia model. I Crit Care. 2014;29(1):184 e9-184 e13.

50. Gitto E, Karbownik M, Reiter RJ, Tan DX, Cuzzocrea S, Chiurazzi P, et al. Effects of melatonin treatment in septic newborns. Pediatr Res. 2001;50(6):756-60.

51. Lorente L, Martin MM, Abreu-Gonzalez P, de la Cruz T, Ferreres I Sole-Violan J, et al. Serum melatonin levels are associated with mortality in severe septic patients. J Crit Care. 2015;30(4):860 e1-6.

52. Xing HY, Ling YL, Meng AH, Zhao XY, Huang XL. [Melatonin improves vascular reactivity of endotoxemia rats]. Sheng Li Xue Bao. 2005;57(3):367-72.

53. Sener G, Toklu H, Kapucu C, Ercan F, Erkanli G, Kacmaz A, et al. Melatonin protects against oxidative organ injury in a rat model of sepsis. Surg Today. 2005;35(1):52-9.

54. Paskaloglu K, Sener G, Kapucu C, Ayanoglu-Dulger G. Melatonin treatment protects against sepsis-induced functional and biochemical changes in rat ileum and urinary bladder. Life Sci. 2004;74(9):1093-104

55. Ortiz F, Garcia JA, Acuna-Castroviejo D, Doerrier C, Lopez A, Venegas $\mathrm{C}$, et al. The beneficial effects of melatonin against heart mitochondrial impairment during sepsis: inhibition of iNOS and preservation of nNOS. J Pineal Res. 2014;56(1):71-81.

56. Wu JY, Tsou MY, Chen TH, Chen SJ, Tsao CM, Wu CC. Therapeutic effects of melatonin on peritonitis-induced septic shock with multiple organ dysfunction syndrome in rats. J Pineal Res. 2008;45(1):106-16.

57. Carrillo-Vico A, Lardone PJ, Naji L, Fernandez-Santos JM, MartinLacave I, Guerrero JM, et al. Beneficial pleiotropic actions of melatonin in an experimental model of septic shock in mice: regulation of pro-/anti-inflammatory cytokine network, protection against oxidative damage and anti-apoptotic effects. J Pineal Res. 2005;39(4):400-8.

58. Martin M, Macias M, Escames G, Reiter RJ, Agapito MT, Ortiz GG, et al.Melatonin-induced increased activity of the respiratory chain complexes I and IV can prevent mitochondrial damage induced by ruthenium red in vivo. J Pineal Res. 2000;28(4):242-8.

59. Lowes DA, Webster NR, Murphy MP, Galley HF. Antioxidants that protect mitochondria reduce interleukin-6 and oxidative stress, improve mitochondrial function, and reduce biochemical markers of organ dysfunction in a rat model of acute sepsis. Br J An aesth. 2013;110(3):472-80.

60. Fink T, Glas M, Wolf A, Kleber A, Reus E, Wolff M, et al. Melatonin receptors mediate improvements of survival in a model of polymicrobial sepsis. Crit Care Med. 2014;42(1):e22-31.

61. Fulia F, Gitto E, Cuzzocrea S, Reiter RJ, Dugo L, Gitto P, et al. Increased levels of malondialdehyde and nitrite/nitrate in the blood of asphyxiated newborns: reduction by melatonin. J Pinea Res. 2001;31(4):343-9.

62. Sahib AS, Al-Jawad FH, Alkaisy AA. Effect of antioxidants on the incidence of wound infection in burn patients. Ann Burns Fire Disasters. 2010;23(4):199-205.

63. Fink M. Cytopathic hypoxia in sepsis. Acta Anaesthesiol Scand Suppl.1997;110:87-95.

64. Boekstegers P, Weidenhofer S, Pilz G, Werdan K. Periphera oxygen availability within skeletal muscle in sepsis and septic shock: comparison to limited infection and cardiogenic shock Infection. 1991;19(5):317-23. 
65. Sair M, Etherington PJ, Peter Winlove C, Evans TW. Tissue oxygenation and perfusion in patients with systemic sepsis. Crit Care Med. 2001;29(7):1343-9.

66. Hayes MA, Timmins AC, Yau EH, Palazzo M, Watson D, Hinds CJ. Oxygen transport patterns in patients with sepsis syndrome or septic shock: influence of treatment and relationship to outcome. Crit Care Med.1997;25(6):926-36.

67. Sjovall F, Morota S, Asander Frostner E, Hansson MJ, Elmer E. Cytokine and nitric oxide levels in patients with sepsis--temporal evolvement and relation to platelet mitochondrial respiratory function. PLoS One. 2014;9(5):e97673.

68. Protti A, Fortunato F, Caspani ML, Pluderi M, Lucchini V, Grimoldi $\mathrm{N}$, et al. Mitochondrial changes in platelets are not related to those in skeletal muscle during human septic shock. PLoS One. $2014 ; 9$ (5).

69. Grundler K, Angstwurm M, Hilge R, Baumann P, Annecke T, Crispin $\mathrm{A}$, et al. Platelet mitochondrial membrane depolarization reflects disease severity in patients with sepsis and correlates with clinical outcome. Crit Care. 2014;18(1):R31.

70. Yamakawa K, Ogura H, Koh T, Ogawa Y, Matsumoto N, Kuwagata Y, et al. Platelet mitochondrial membrane potential correlates with severity in patients with systemic inflammatory response syndrome. J Trauma Acute Care Surg. 2013;74(2):411-7.

71. Sjovall F, Morota S, Hansson MJ, Friberg H, Gnaiger E, Elmer E. Temporal increase of platelet mitochondrial respiration is negatively associated with clinical outcome in patients with sepsis. Crit Care. 2010;14(6):R214

72. Sjovall F, Morota S, Persson J, Hansson MJ, Elmer E. Patients with sepsis exhibit increased mitochondrial respiratory capacity in peripheral blood immune cells. Crit Care. 2013;17(4):R152.

73. Japiassu AM, Santiago AP, d'Avila JC, Garcia-Souza LF, Galina A Castro Faria-Neto HC, et al. Bioenergetic failure of human peripheral blood monocytes in patients with septic shock is mediated by reduced F1Fo adenosine-5'-triphosphate synthase activity. Crit Care Med. 2011;39(5):1056-63.

74. Garrabou G, Moren C, Lopez S, Tobias E, Cardellach F, Miro O, et al. The effects of sepsis on mitochondria.JInfect Dis. 2012;205(3):392400.

75. Belikova I, Lukaszewicz AC, Faivre V, Damoisel C, Singer M, Payen D. Oxygen consumption of human peripheral blood mononuclear cells in severe human sepsis. Crit Care Med. 2007;35(12):2702-8.

76. Adrie C, Bachelet M, Vayssier-Taussat M, Russo-Marie F, Bouchaert I, Adib-Conquy M, et al. Mitochondrial membrane potential and apoptosis peripheral blood monocytes in severe human sepsis. Am J Respir Crit Care Med. 2001;164(3):389-95.

77. Carre JE, Orban JC, Re L, Felsmann K, Iffert W, Bauer M, et al. Survival in critical illness is associated with early activation of mitochondrial biogenesis. Am J Respir Crit Care Med. 2010;182(6):74551.

78. Fredriksson K, Tjader I, Keller P, Petrovic N, Ahlman B, Scheele C, et al. Dysregulation of mitochondrial dynamics and the muscle transcriptome in ICU patients suffering from sepsis induced multiple organ failure. PLoS One. 2008;3(11):e3686.

79. Fredriksson K, Hammarqvist F, Strigard K, Hultenby K, Ljungqvist O, Wernerman J, et al. Derangements in mitochondrial metabolism in intercostal and leg muscle of critically ill patients with sepsis-induced multiple organ failure. Am J Physiol Endocrinol Metab. 2006;291(5):E1044-50.

80. Brealey D, Brand M, Hargreaves I, Heales S, Land J, Smolenski R, et al. Association between mitochondrial dysfunction and severity and outcome of septic shock. Lancet. 2002;360(9328):219-23.

81. Gasparetto A, Corbucci GG, Candiani A, Gohil K, Edwards RH. Effect of tissue hypoxia and septic shock on human skeletal muscle mitochondria. Lancet. 1983;2(8365-66):1486.

82. Poderoso JJ, Boveris A, Jorge MA, Gherardi CR, Caprile AW, Turrens J, et al. [Mitochondrial function in septic shock]. Medicina (B Aires).1978;38(4):371-7.

83. Lorente L, Martin MM, Lopez-Gallardo E, Iceta R, Sole-Violan J, Blanquer J, et al. Platelet cytochrome c oxidase activity and quantity in septic patients. Crit Care Med.2011;39(6):1289-94.

84. Lorente L, Martin MM, Lopez-Gallardo E, Iceta R, Blanquer J, SoleViolan J, et al. Higher platelet cytochrome oxidase specific activity in surviving than in non-surviving septic patients. Crit Care. 2014;18(3):R136

85. Lorente L, Martin MM, Lopez-Gallardo E, Blanquer J, Sole-Violan J, Labarta L, et al. Decrease of oxidative phosphorylation system function in severe septic patients. J Crit Care. 2015.

86. Piel DA, Gruber PJ, Weinheimer CJ, Courtois MR, Robertson $\mathrm{CM}$, Coopersmith CM, et al. Mitochondrial resuscitation with exogenous cytochrome $\mathrm{c}$ in the septic heart. Crit Care Med. 2007;35(9):2120-7.

87. Piel DA, Deutschman CS, Levy RJ. Exogenous cytochrome C restores myocardial cytochrome oxidase activity into the late phase of sepsis. Shock. 2008;29(5):612-6.

88. Verma R, Huang Z, Deutschman CS, Levy RJ. Caffeine restores myocardial cytochrome oxidase activity and improves cardiac function during sepsis. Crit Care Med. 2009;37(4):1397-402.

89. Groening P, Huang Z, La Gamma EF, Levy RJ. Glutamine restores myocardial cytochrome $\mathrm{C}$ oxidase activity and improves cardiac function during experimental sepsis. JPEN J Parenter Enteral Nutr. 2011;35(2):249-54

90. Yang Y, Shou Z, Zhang P, He Q, Xiao H, Xu Y, et al. Mitochondrial DNA haplogroup R predicts survival advantage in severe sepsis in the Han population. Genet Med.2008;10(3):187-92.

91. Baudouin SV, Saunders D, Tiangyou W, Elson JL, Poynter J, Pyle A, et al. Mitochondrial DNA and survival after sepsis: a prospective study. Lancet. 2005;366(9503):2118-21.

92. Lorente L, Iceta R, Martin MM, Lopez-Gallardo E, Sole-Violan J, Blanquer J, et al. Survival and mitochondrial function in septic patients according to mitochondrial DNA haplogroup. Crit Care. 2012;16(1):R10.

93. Lorente L, Iceta R, Martin MM, Lopez-Gallardo E, Sole-Violan J, Blanquer J, et al. Severe septic patients with mitochondrial DNA haplogroup JT show higher survival rates: a prospective, multicenter, observational study. PLoS One. 2013;8(9):e73320.

94. Bellizzi D, Cavalcante P, Taverna D, Rose G, Passarino G, Salvioli $\mathrm{S}$, et al. Gene expression of cytokines and cytokine receptors is modulated by the common variability of the mitochondrial DNA in cybrid cell lines. Genes Cells. 2006;11(8):883-91.

95. Hack CE, De Groot ER, Felt-Bersma RJ, Nuijens JH, Strack Van Schijndel RJ, Eerenberg-Belmer AJ, et al. Increased plasma levels of interleukin-6 in sepsis. Blood.1989;74(5):1704-10. 